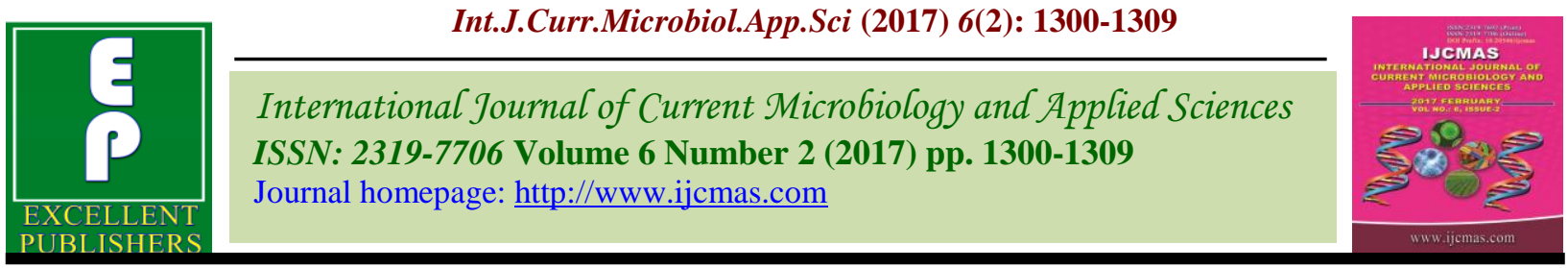

Original Research Article

http://dx.doi.org/10.20546/ijcmas.2017.602.147

\title{
Effect of Condensation Method on Quality Attribute of Kulfi
}

\author{
Kiran Nagajjanavar ${ }^{1}$, Menon Rekha Ravindra ${ }^{2}$, M. Manjunatha ${ }^{2}$, \\ B. Surendra Nath ${ }^{2}$ and B.V. Balasubramanyam ${ }^{2}$ \\ ${ }^{1}$ College of Horticulture, Sirsi- 581401, India \\ ${ }^{2}$ SRS of ICAR-NDRI, Bangalore- 560030, India \\ *Corresponding author
}

\begin{tabular}{|c|c|}
\hline & A B S T R A C T \\
\hline $\begin{array}{l}\text { K e y w or d s } \\
\text { Condensation, } \\
\text { Freezing, Kulfi }\end{array}$ & $\begin{array}{l}\text { Condensation is cumulative process for the total solid by evaporating the water content in } \\
\text { the product. The method of condensation varies with product to product preparation or by } \\
\text { the facility of the processing plant. The three type of condensation methods like open pan } \\
\text { condensation, vacuum pan condensation and combination of vacuum pan and open pan } \\
\text { methods were used to condense the pre standardized milk ( } 5 \% \text { fat and } 8 \% \text { SNF) up to two }\end{array}$ \\
\hline Article Info & \\
\hline $\begin{array}{l}\text { Accepted: } \\
\text { 22 January } 2017 \\
\text { Available Online: } \\
\text { 20 February } 2017\end{array}$ & $\begin{array}{l}\text { the separation of the cream layer. The freezing of kulfi was completed by immersion } \\
\text { freezing in liquid brine solution. The effect of the condensation method on freezing time, } \\
\text { melting rate, hardness and sensory attribute of the kulfi was measured. The open pan } \\
\text { condensation method was ascertained better in maintaining the body and texture, colour } \\
\text { and melting rate of kulfi as compare to other methods. }\end{array}$ \\
\hline
\end{tabular}

\section{Introduction}

Frozen desserts are delicious and calorie-rich foods relished by all age groups and popular throughout the world. Kulfi is 500 year old a popular frozen dessert (Aneja, 1992) of Indian origin and it occupies a privileged position amongst the traditional Indian dairy products. Kulfi is also known as qulfi, kulfa, kulphy etc (Pandit, 2004). The word kulfi derives its origin from the Hindustani word kulaf meaning a 'lock' or a 'container' that has to be unlocked. And, indeed the recess of the metal cone that encases the frozen delight has to be pried open to release the confection (Aneja, 1992). Kulfi is very popular in many parts of the country mainly due to its palatability and low price. It is similar to ice cream in formulation and processing, but differs from ice cream in that it contains little or no air. It is conventionally produced by concentrating whole milk to about two folds followed by addition of sugar and freezing it in aluminium or plastic moulds. The mixture should be suitably heat treated before freezing. The product shall have a pleasant agreeable aroma and taste with uniform consistency, free from big sized crystals and coagulated milk particles (Pal, 2006). Then the freezing of kulfi is done by immersion freezing in an ice and salt or liquid brine solution or by extrusion through a freezer with very low overrun.

Condensation is cumulative process for the total solid by evaporating the water content in 
the product. The method of condensation varies with product to product preparation or by the facility of the processing plant

The choice of dairy ingredients and formulation of kulfi mix are determined by regulatory standards, the desired quality of frozen dessert, marketing strategy, consumer demand, relative price and availability of ingredients. But, the body or consistency of kulfi is related to the mechanical strength of the mix and its resistance to melting.

Information regarding the engineering aspects of kulfi freezing processing including effect of condensation methods and their influence on product structure and quality are sparsely reported.

These aspects are important in the design, analysis and control of the process and product quality.

In light of these points, a research study has been taken to comparatively evaluate the three types of condensation methods like open pan condensation, vacuum pan condensation and combination of vacuum pan and open pan methods effect on quality attributes of the kulfi.

\section{Materials and Methods}

The different condensation methods adopted for the concentration of mix to prepare the $k u l f i$ is detailed in figure 1 .

\section{Collection and standardization of milk}

Fresh clean Deoni cow milk was collected from the ICAR- National Dairy Research Institute (SRS), Bengaluru, Livestock Research Center and standardized to $5 \%$ fat and $8.5 \%$ SNF by weight. This standardized Deoni cow milk was used throughout this study.

\section{Condensation}

Condensation is cumulative process for the total solid by evaporating the water content in the product. The three type of condensation methods like open pan condensation, vacuum pan condensation and combination of vacuum pan and open pan methods were used to condense the pre standardized milk $(5 \%$ fat and $8.5 \% \mathrm{SNF}$ ) up to two folds

\section{Open pan condensation}

After adding the $13 \%$ cane sugar computed (on product basis) to the standardized milk the milk is concentrated in the open jacket steam vessel (make; Jacket.HYD, T.P.60 P.S.L.G) up to two fold level $(2: 1)$, the maximum temperature of kulfi mix has achieved during concentration was $102-103^{\circ} \mathrm{C}$ (Fig. 2.).

\section{Vacuum pan condensation}

In vacuum pan condensation method, after addition of $13 \%$ sugar to the mix (computed on product basis), single effect evaporator (APV, Kolkatta) with water evaporation capacity of 20L/h (Fig. 3) was used for concentrating the kulfi mix to the desired total solids (TS) up 2:1 level.

All the concentrations were carried out at $0.829 \mathrm{~kg} / \mathrm{cm}^{2}$ vacuum pressure, which corresponded to a temperature of concentration of $63-65^{\circ} \mathrm{C}$.

\section{Combination of vacuum pan and open pan condensation}

Pre-standardized milk was initially concentrated in the vacuum pan nearly to the two folds by maintaining $0.829 \mathrm{~kg} / \mathrm{cm}^{2}$ vacuum pressure which corresponded to a temperature of concentration of $63-65^{\circ} \mathrm{C}$, then $13 \%$ sugar (computed on product basis) was added to concentrated milk and desired 
concentration was achieved through open pan condensation at about $102-103^{\circ} \mathrm{C}$.

\section{Freezing}

The mix was cooled to ambient temperature with continuous agitation to avoid the separation of cream layer, The freezing of kulfi was completed by immersion freezing in liquid brine ( $26 \% \mathrm{NaCl}$ by wt.) solution.

\section{Packing and hardening}

After freezing the kulfi was taken out from the cone and wrapped in butter paper and kept it for $8 \mathrm{~h}$ for hardening at $-18^{\circ} \mathrm{C}$ in Celfrost Chest freezer (Make: CF-100, Volume: 1001trs.). A hardening is reported to remove heat to quickly as possible from the ice cream (Hui, 2006) in order to inhibit the ripening/recrystalization of the ice crystals.

\section{Analytical methods}

\section{Melting rate}

Melting stability of kulfi was determined as per the method described by Raju et al., (1989). The material consist of drawing $70 \mathrm{~g}$ of kulfi sample on to a wire net (250 pores per sq. inch) placed on a funnel over a measuring jar immediately after removal from the hardening chamber for 15 minutes at $35 \pm$ $1{ }^{\circ} \mathrm{C}$ (Fig. 4). The amount of kulfi in ml melted in 15 minutes was noted as melting stability and the melting rate was expressed as $\mathrm{ml} / 15$ $\min$.

\section{Hardness}

Textural profile analysis (TPA) was performed using TA.XT Plus Texture Analyzer (Stable Micro Systems, Texture Technologies Corp., Goldaming, UK) equipped with $50 \mathrm{~kg}$ load cell (Fig. 5). The frozen hardened kulfi sample $10 \mathrm{~mm}$ thickness and $35 \mathrm{~mm}$ diameter sample after immediately removing from the freezer was compressed in a reciprocating motion to give shearing force texture profile curve. The compression depth of $10 \mathrm{~mm}$ was achieved using a Warner Bratzler Blade (HDP/WBR) set with rectangular slot blade, The blade had a knife edge at one end and a flat guillotine edge at the other. In operation, the blade was firmly held by means of the blade holder which screws directly into the Texture Analyzer.

Once the trigger force of $2 \mathrm{~g}$ was attained, the knife edge proceeded to shear the kulfi to the depth of $10 \mathrm{~mm}$ before returning to its original position at constant speed $(10 \mathrm{~mm} / \mathrm{s})$. the maximum force expressed by sample at the point of return of the probe was measured as sample hardness, the greater the value the harder the sample.

\section{Measurement of colour}

The colour of kulfi cone after hardening was measured using a computer based image analysis technique. The samples were placed on a flatbed scanner (Canoscan 9000F, Mark II) and scanned at 600 dpi resolution. The images were then imported into Adobe Photoshop 7.0 software and the 'L', 'a' and ' $b$ ' values were obtained from the histogram window (Adobe Photoshop 7.0 User Guide for Macintosh and Windows, 1998). The software uses a scale, ranging from 0 to 255 , to characterize L (lightness), ' $a$ ' and ' $b$ '. These values were converted into CIELAB $\mathrm{L}^{*}, \mathrm{a}^{*}$ and $\mathrm{b}^{*}$ values using the following formulae (Yam and Papadakis, 2004).

$$
\begin{aligned}
& L^{*}=\left[\frac{L}{255}\right] \times 100 \\
& a^{*}=\left[\frac{240 a}{255}\right]-120 \\
& b^{*}=\left[\frac{240 b}{255}\right]-120
\end{aligned}
$$


Yellowness index (YI), Whiteness Index (WI) and Browning Index (BI) were calculated from the $\mathrm{L}^{*}, \mathrm{a}^{*}$ and $\mathrm{b}^{*}$ values using the following formulae.

$$
\begin{aligned}
& \mathrm{YI}=142.86\left(\frac{\mathrm{b}^{*}}{\mathrm{~L}^{*}}\right)(\text { Pagliarini } \text { et al., 1990) } \\
& W I=100 \sqrt{\left(100-L^{*}\right)^{2}+a^{* 2}+b^{* 2}} \\
& \text { (Pagliarini et al., 1990) }
\end{aligned}
$$

$$
B I=100(L-0.31) / 0.172
$$

Where, $\mathrm{L}^{*}, \mathrm{a}^{*}$ and $\mathrm{b}^{*}$ represented the colour values of kulfi after hardening.

\section{Sensory evaluation of kulfi}

The sensory evaluation was done by a selected panel of judges on a 9 point hedonic scale for appearance, flavour, melting characteristics, body and texture and overall acceptability. A score of 9 corresponded to highest acceptability while a score of 1 corresponded to least acceptability of the products (Dewangan, 2012).

\section{Results and Discussion}

The effect of the condensation method on freezing point, melting rate, hardness, colour parameter and sensory attribute of the kulfi were compared and is discussed below.

\section{Freezing point}

The freezing curve for the kulfi mix prepared using the different condensation methods is presented in figure 6. It can be seen that the different condensation methods did not have any considerable effect on the freezing point of kulfi mix and the freezing curve followed near identical path for the kulfi mix prepared using all the three condensation methods. This could be due to the constant total solids content maintained in kulfi mix used in the study for different condensation methods. A similar observation was also reported by Jie et $a l ., 2003$ who deduced that the freezing point depended on the total solids present in the solution.

\section{Melting rate}

The effect of different condensation methods on the melting rate $(\mathrm{ml} / 15 \mathrm{~min})$ of kulfi is graphically represented in figure 7 . From the figure, it was observed the melting rate of VP condensation method ( $28 \mathrm{ml} / 15 \mathrm{~min})$ was higher compared to 24 and $24.5 \mathrm{ml} / 15 \mathrm{~min}$ for $\mathrm{OP}$ and $\mathrm{VP}+\mathrm{OP}$ method respectively. The melting rate of VP treated sample was significantly higher than that of other treatments; while there was no significant difference noticed in melting rate of OP treated sample and VP+OP samples.

The lower melting rate score for OP and $\mathrm{VP}+\mathrm{OP}$ treated kulfi sample could be attributed to lower ice mass fraction formed due to reduced free water proportion. At elevated temperatures (as in the case of open pan processing), the whey protein produces heat induced gels that are capable of holding large amount of water and other food components (Fox and Mcsweeney, 2003). This bound water probably reduced the volume of free water in the kulfi mix for freezing, leading to lower melting rate.

\section{Hardness}

The hardness value (N) of kulfi samples prepared using different condensation methods is shown in figure 7 . The hardness value $(\mathrm{N})$ recorded for kulfi sample treated by VP condensation method was 42, as against 34 and nearly 35 observed for OP and VP+OP condensation methods, respectively. The hardness value of VP treated sample was significantly higher than that of kulfi mix 
condensed by other two methods, due to increased mass fraction of ice content in the final frozen kulfi samples.

\section{Colour index of kulfi}

The colour index of kulfi was estimated using the Eq. 4, 5 and 6 is graphically represented in figure 8 . The yellowness index computed for $\mathrm{OP}$ and VP+OP methods was 31 and 32, respectively. It was found that VP condensation method sample achieved very poor yellowness index of 21. The increase in the YI in OP method OP+VP method could be due to the complete denaturation of the protein and caramelization of sugar level at elevated temperature $\left(102^{\circ} \mathrm{C}\right)$ during concentration process in the open pan as compared to VP method $\left(63-65^{\circ} \mathrm{C}\right)$.

The browning index of the kulfi samples prepared using the three condensation methods followed a parallel trend to that of yellowness index, while the whiteness index of the samples reflected a reverse trend to yellowness index.

\section{Sensory evaluation}

\section{Color and appearance}

From table 1, it can be seen that the average score for color and appearance awarded for VP kulfi was 6.5 , as against 7.5 for the samples subjected to $\mathrm{OP}$ and $\mathrm{OP}+\mathrm{VP}$, respectively. The color and appearance score of $\mathrm{OP}$ and $\mathrm{OP}+\mathrm{VP}$ sample was significantly higher than that of VP treated kulfi samples. The lower color and appearance score for VP treated kulfi was mainly due to lack of desirable brownish appearance. This could be mainly due to reduction in condensation temperature in VP treatment, which is required for development of desirable brown color in kulfi through caramelization. The other two treatments OP and VP+OP ascertained same color and appearance score due to the effect of elevated temperature during condensation.

\section{Body and texture}

Body and texture score awarded for VP kulfi was 7, as against 9 for the samples subjected to $\mathrm{OP}$ and $\mathrm{OP}+\mathrm{VP}$ respectively. Between OP and $\mathrm{VP}+\mathrm{OP}$ treated kulfi there was no significant difference in body and texture score (Table 1). The low body and texture score of VP condensed kulfi was attributed to its high melting characteristic and hence softer body.

\section{Flavor}

Flavor score awarded for VP kulfi was 7.5, as against 8.5 and 8 for the samples subjected to $\mathrm{OP}$ and $\mathrm{OP}+\mathrm{VP}$ respectively. Between $\mathrm{OP}$ and $\mathrm{VP}+\mathrm{OP}$ treated kulfi there was no significant difference in flavor score (Table 1). Elevated temperature during open pan processing aided in the development of a caramelized flavor in the kulfi, which resulted in higher flavor scores during sensory evaluation.

\section{Melting characteristic}

One of the desirable attributes for kulfi is its ability to retain its frozen state during consumption without any meltdown or rundown. Hence, the sensory panel was asked to score for the melting characteristic of the product during sensory evaluation. From table 1 , it can be seen that the melting characteristic score awarded for VP kulfi was 6.5, as against 8.5 the samples subjected to $\mathrm{OP}$ and $\mathrm{OP}+\mathrm{VP}$ respectively. Between OP and $\mathrm{VP}+\mathrm{OP}$ treated kulfi there was no significant difference in melting characteristic score. The lower melting characteristic score for $\mathrm{OP}$ and $\mathrm{VP}+\mathrm{OP}$ treated kulfi sample was mainly due to less ice mass fraction (free water) proportion. 


\section{Overall acceptability}

The overall acceptability score of VP treated kulfi sample awarded was around 6.8 , as against 8.3 and 8.5 for treatment $\mathrm{OP}$ and $\mathrm{VP}+\mathrm{OP}$. Between OP and VP+OP treatment techniques, no significant difference was observed on overall acceptability score but VP treated kulfi the overall acceptability score significantly decreased as compared to other treatments and observation reported in table 1 .

Table.1 Sensory score for quality attributes of kulfi for different condensation methods

\begin{tabular}{|l|c|c|c|}
\hline Sensory parameters & Vacuum Pan & Open Pan & Vacuum pan+ Open Pan \\
\hline Colour and appearance & $6.5^{\mathrm{a}}$ & $7.5^{\mathrm{b}}$ & $7.5^{\mathrm{b}}$ \\
\hline Flavor & $7.5^{\mathrm{a}}$ & $8^{\mathrm{a}}$ & $8^{\mathrm{a}}$ \\
\hline Body and Texture & $7.5^{\mathrm{a}}$ & $9^{\mathrm{b}}$ & $9^{\mathrm{b}}$ \\
\hline Melting characteristic & $6.5^{\mathrm{a}}$ & $8.5^{\mathrm{b}}$ & $8.5^{\mathrm{b}}$ \\
\hline Overall acceptability & $6.87^{\mathrm{a}}$ & $8.37^{\mathrm{b}}$ & $8.5^{\mathrm{b}}$ \\
\hline
\end{tabular}

*Results are means of six measurements for each treatment

Fig.1 Process flow for the preparation of kulfi using different condensation methods

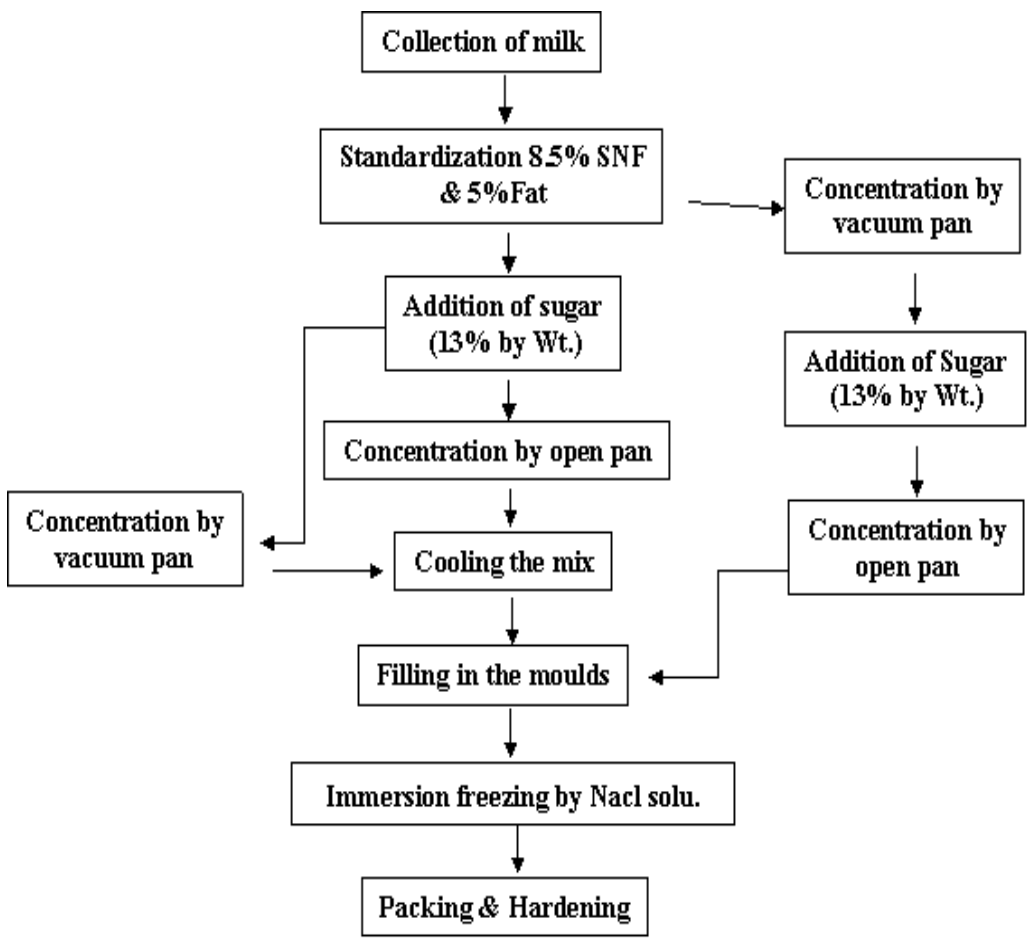


Fig.2 Open pan condenser

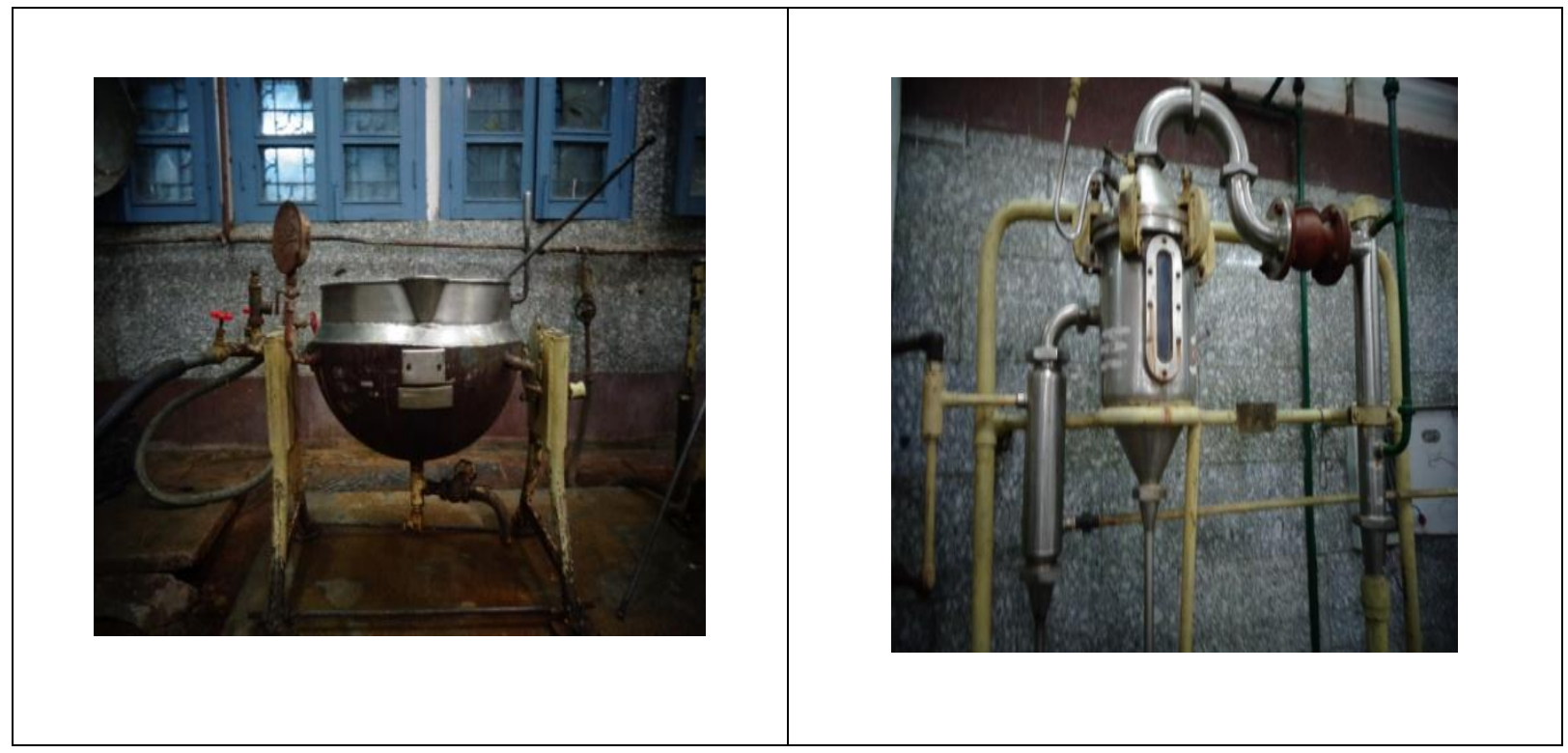

Fig.4 Experimental setup for determination of melting rate
Fig.3 Single effect evaporator

Fig.5 TA.XT Plus Texture Analyzer

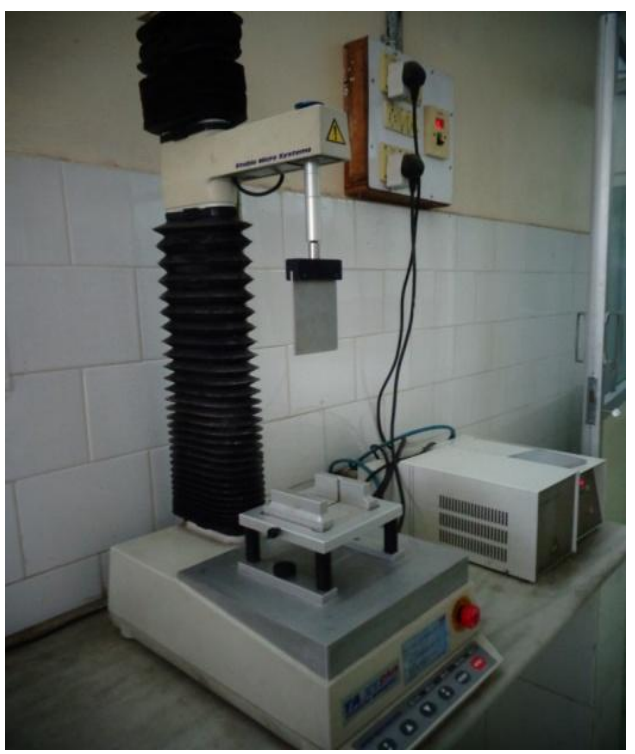


Fig.6 Freezing curves of the kulfi with different condensation methods

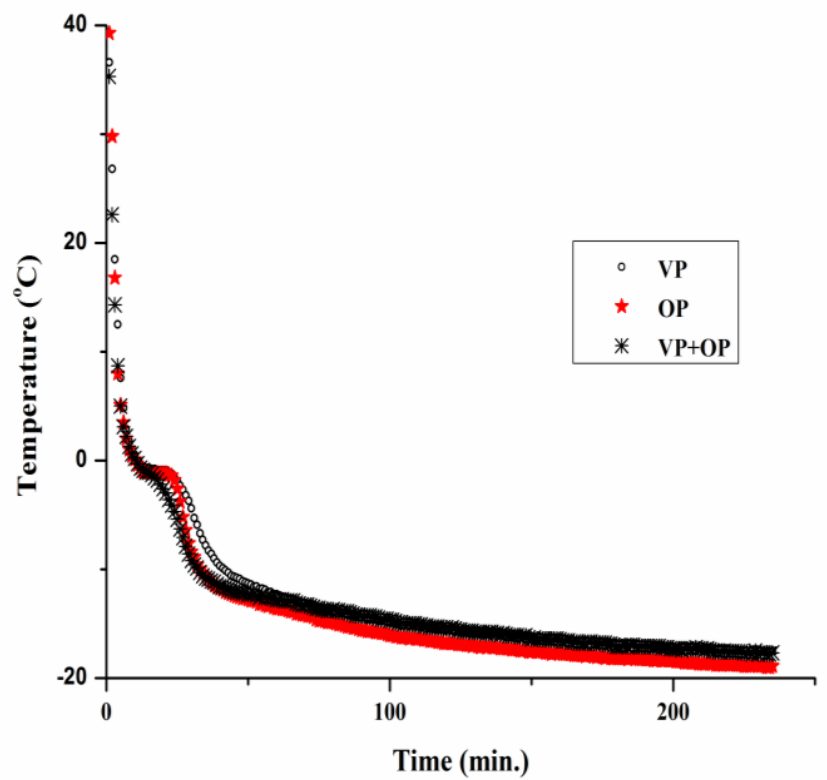

VP: Vacuum pan condensation, OP: Open pan condensation and VP+OP: Combination of OP and VP *Results are means of three measurements for each treatment

Fig.7 Melting rate and hardness of the kulfi with different condensation methods

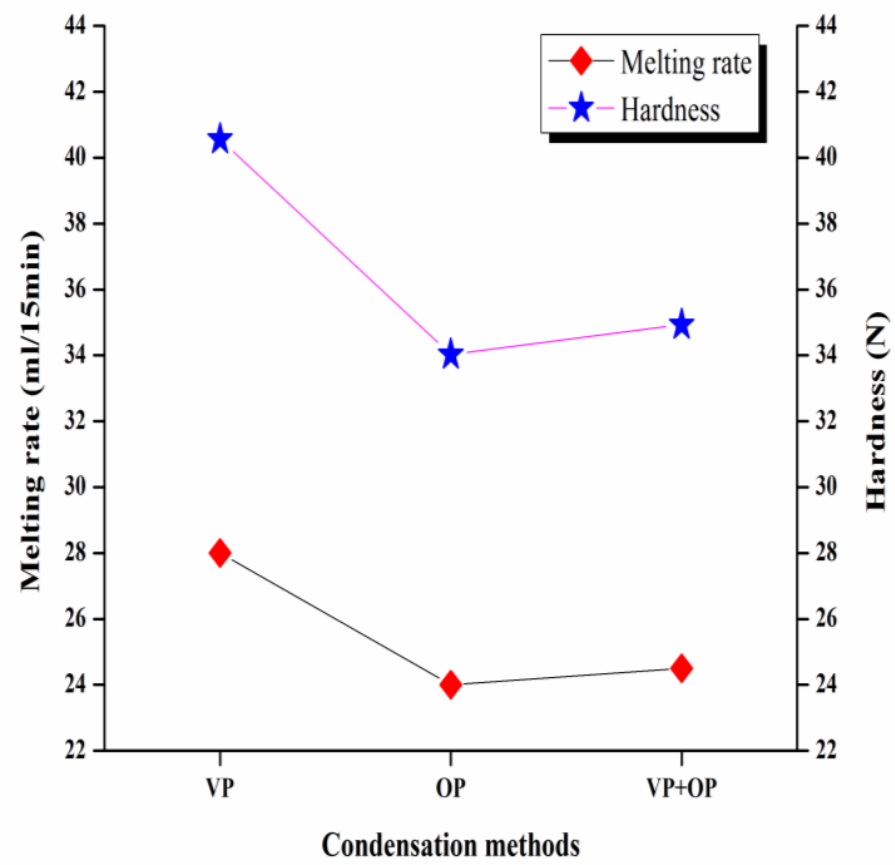

VP: Vacuum pan condensation, OP: Open pan condensation and VP+OP: Combination of OP and VP *Results are means of three measurements for each treatment 
Fig.8 Colour index of the kulfi with different condensation methods

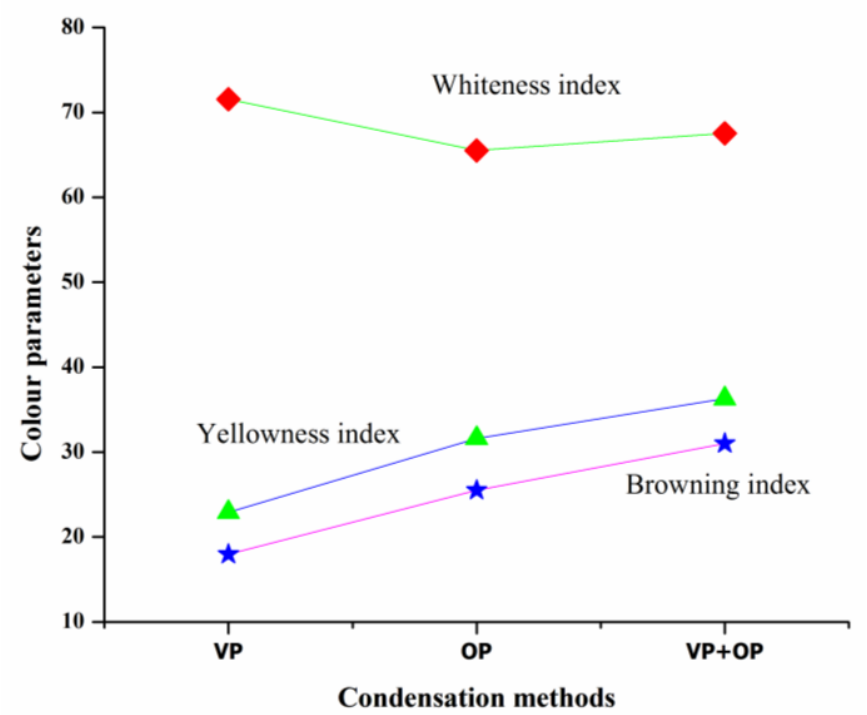

VP: Vacuum pan condensation, OP: Open pan condensation and VP+OP: Combination of OP and VP *Results are means of three measurements for each treatment

In conclusion, the effect of the condensation method on freezing time, melting rate, hardness, colour index and sensory attribute of the kulfi was measured. The open pan condensation method and combination methods were ascertained better in maintaining the body and texture, colour and melting rate of kulfi as compare to vacuum pan methods, but the combination condensation method is time and energy consuming as compare to other two methods.

\section{Acknowledgement}

This research was supported by ICARNational Dairy Research Institute (SRS), Bangalore

\section{References}

Aneja RP (1992). Traditional milk specialities: A survey. In: Dairy India. Devarsons Stylish Printing Press, New Delhi: 269.
Dewangan AK (2012). Manufacture of kulfi mix in scraped surface heat exchanger and its performance evaluation. M.Tech. Thesis (unpublished), Sheth M.C. College of dairy science Anand Agricultural University, Anand (Gujarat).

Fox PF and Mcsweeney PLH (2003). Advance dairy chemistry Volume -1 proteins third editions, Kluwer Academic/Plenum publishers. New York.

Hui YH (2006). Handbook of food science, technology and engineering. Volume 4, CRC Press.

Jie W, Lite L and Yang D (2003). The correlation between freezing point and soluble solids of fruits. Journal of Food Engineering. 60: 481-484.

Pagliarini E, Vernile M and Peri C (1990). Kinetic study on color changes in milk due to heat. Journal of Food Science. 55 (6):1766-1767. 
Pal D (2006). Developments in traditional dairy products-lecture compendium. Centre of advanced studies, Dairy Technology division, National Dairy Research Institute, Karnal, India: 5557.

Pandit P (2004). Technology studies on the manufacture of kulfi using artificial sweeteners. M. Tech. Thesis (unpublished), National Dairy Research Institute, Karnal, India.
Raju AA, Ali MP, Reddy KK, Reddy CR and Rao MR (1989). Studies on preparation and quality of kulfi. The Indian Journal of Dairy Science. 17.

Yam KL and Papadakis SE (2004). A simple digital imaging method for measuring and analyzing color of food surfaces. Journal of Food Engineering. 61(1):137-142.

\section{How to cite this article:}

Kiran Nagajjanavar, Menon Rekha Ravindra, M. Manjunatha, B. Surendra Nath and B.V. Balasubramanyam. 2017. Effect of Condensation Method on Quality Attribute of Kulfi. Int.J.Curr.Microbiol.App.Sci. 6(2): 1300-1309. doi: http://dx.doi.org/10.20546/ijcmas.2017.602.147 